\title{
The Correlation between EGFR Mutation Status and DNA Content of Lung Adenocarcinoma Cells in Pleural Effusion
}

\author{
Yun Du ${ }^{\varpi}$, Xiao Guo, Rui Wang, Yang Ma, Yan Zhang, Ying Liu, Lvli Dong, Juan Wu, Xiaokun Ji, Heng \\ Wang \\ Department of Cytology, The Fourth Hospital of Hebei Medical University, Shijiazhuang, China \\ $\square$ Corresponding author: Professor Yun Du, MD, PhD., Dept of Cytology, The Fourth Hospital of Hebei Medical University, Jiankang Road 12, Shijiazhuang, \\ Hebei Province 050011, China. Tel: +86 0311-86095310; Email: yydd40@126.com; yydd40@hebmu.edu.cn \\ (c) The author(s). This is an open access article distributed under the terms of the Creative Commons Attribution License (https://creativecommons.org/licenses/by/4.0/). \\ See http:/ /ivyspring.com/terms for full terms and conditions.
}

Received: 2019.07.22; Accepted: 2020.01.03; Published: 2020.02.06

\begin{abstract}
Objectives: Lung adenocarcinomas with or without epidermal growth factor receptor (EGFR) mutations have shown different drug effects against EGFR inhibitors. But it is not very clear if EGFR mutation status affects the biological behavior of lung adenocarcinoma, because tumor gene regulation is very complicated and can be affected by many factors. We aimed to explore if EGFR mutation status is related with tumor malignant degree by investigating the relevance of EGFR mutation status with DNA content and aneuploid peaks of lung adenocarcinoma cells in pleural fluids without using EGFR-TKIs.

Materials and Methods: 591 cases of lung adenocarcinoma patients in Hebei Tumor Hospital who had undergone EGFR gene detection and DNA quantitative analysis were collected from January 2012 to August 2018.They were divided into two groups: EGFR mutant group and non-mutant group. EGFR mutations were detected by Amplification Refractory Mutation System (ARMS) and ABI 7500 Fluorescence quantitative PCR with pleural effusions. DNA content and aneuploid peaks were detected by LD DNA image cytometry (DNA-ICM). Rank-sum test of SPSS 16 was used for statistical analysis.

Results: The maximum DI, the mean DI of the first 20 cells greater than $5 \mathrm{C}$, the percentage of cells greater than $5 \mathrm{C}$ and the number of cells greater than $9 \mathrm{C}$ of the first 20 cells in the mutant group were all higher than those in the non-mutant group, having statistical significance $(p<0.001)$; the peaks of aneuploid cells in the mutant group occurred more often than those in the non-mutant group, having statistical significance $(p<0.001)$.

Conclusions: Our study has shown that advanced lung adenocarcinomas with EGFR-mutations had higher DI values, more aneuploid cells and more frequent aneuploid peaks compared with those without EGFR-mutations, suggesting that advanced lung adenocarcinomas with EGFR mutations are more aggressive than those without EGFR mutations.
\end{abstract}

Key words: Lung adenocarcinoma, EGFR mutation, DNA quantitative analysis

\section{Introduction}

EGFR is a receptor tyrosine kinase that plays fundamental roles not only in physiology but also in cancer, its overexpression and/or mutations have been found in many cancers which may affect the development and progression of cancer [1-4]. In recent years, EGFR targeted drugs have been widely used and achieved significant efficacy in lung adenocarcinoma, and have shown different effects in different EGFR mutation status [5-8]. But the correlation and mechanism of EGFR mutation status with the biological behavior and prognosis of lung adenocarcinoma remain unclear and controversial, and can be interfered by tumor stage, EGFR-TKI medication and other factors. 
DNA aneuploidy is an objective, molecular-based biomarker that reflects cancer genetic instability. Many studies have shown that the aneuploid cells in tumor tissues were associated with tumor malignancy and prognosis [9-14]. But few researches evaluated the biological behavior of lung adenocarcinoma with or without EGFR mutations using DNA content detected by automatic DNA image cytometry. The aim of this study is to explore if and how EGFR mutation status affects the biological behavior of lung adenocarcinoma by detecting the DNA content and aneuploid peaks of advanced lung adenocarcinoma cells with or without EGFR mutations in the absence of EGFR-TKIs.

\section{Materials and Methods}

\subsection{Materials}

591 cases of advanced lung adenocarcinoma patients with pleural effusion in Hebei Tumor Hospital who had undergone EGFR gene detection and DNA quantitative analysis were collected from January 2012 to August 2018. All the patients met our strict inclusion criteria : (1) They were diagnosed with lung adenocarcinoma by two skillful cytologists; (2) They were never received any treatment prior to admission; (3) All of them were in stage IV according to the UICC/AJCC TNM staging system; (4) They and their families agreed to participate in the study and signed the informed consent form; (5) They received EGFR gene mutations test and DNA quantitative analysis; (6) They did not combine other tumors; (7) This study was approved by the Hospital Ethics Committee. They were divided into two groups: EGFR mutant group and non-mutant group. EGFR mutations were detected by Amplification Refractory Mutation System (ARMS) and ABI 7500 Fluorescence quantitative PCR with pleural effusions. DNA content and aneuploid peaks were detected by LD DNA image cytometry (LD DNA-ICM, Landing Med Tech,
Wuhan). Clinical and pathological data of all the patients were obtained from the medical records and telephone follow-ups from patients or their families. Rank-sum test of SPSS 16 was used for statistical analysis.

\subsection{Sampling Method}

2.2.1. As shown in Figure 1, first we used a disposable cell collector to extract and filter part of the pleural effusion(100 300ml), which mechanism was to use a filter membrane with different-size micropores to trap and enrich tumour cells, then the enriched cells were uniformly smeared on 4 ordinary slides and 8 antistripping slides: two of the four ordinary slides were fixed in $95 \%$ alcohol for routine diagnosis; two of the four ordinary slides were fixed in anhydrous ethanol for DNA quantitative analysis; eight anti-stripping slides were fixed in $95 \%$ ethanol for immunocytochemical staining.

2.2.2. The remaining pleural effusion was centrifuged for 2 minutes at $1800 \mathrm{r} / \mathrm{min}$ using a $15 \mathrm{ml}$ tube several times until it was used up, every time the supernatant was discarded and the bottom sediment was retained, finally the total sediment was stored in $20{ }^{\circ} \mathrm{C}$ refrigerator for EGFR gene detection.

\subsection{EGFR mutation detection}

2.3.1. We used AmoyDx DNA extraction kit to extract DNA and used Denovix DS-11 ultraviolet spectrophotometer to detect DNA concentration and purity. OD260/OD280 was within $1.8 \sim 2.0$, the recommended concentration of the DNA from fresh specimens was $0.4 \sim 1 \mathrm{ng} / \mu \mathrm{l}$.

2.3.2. We used ARMS and ABI 7500 Fluorescence quantitative PCR to detect EGFR gene mutation. The procedures were carried out according to AmoyDx EGFR gene mutation detection kit.
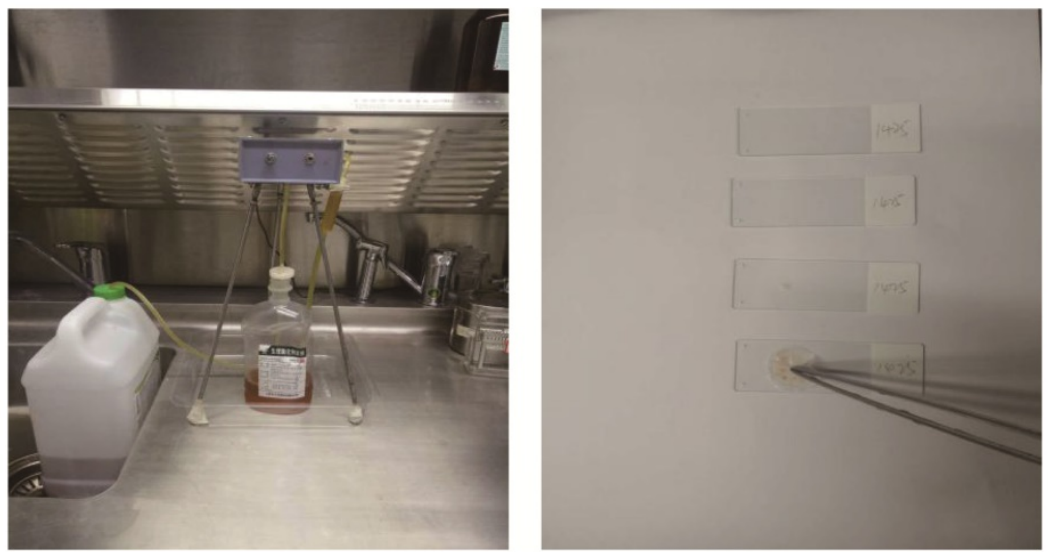

Figure 1. Sampling method 


\subsection{DNA quantitative analysis}

We used LD DNA-ICM to detect DNA content, aneuploid cells and aneuploid peaks, which included an Olympus BX41 microscope, a Wave NP370D2 server, a ueyeM2240 camera, an automatic control platform, and a cell image analysis software. Its mechanism was to determine the nucleus DNA content by measuring the integrated optical density (IOD) of the stained nucleus DNA, using normal epithelial cells and lymphocytes on the same slide as control. The reference cell coefficient of variation $(\mathrm{CV}$, $\mathrm{CV}=$ standard deviation / mean value $\times 100 \%$ ) was less than $5 \%$.

DNA Index (DI) was used to represent DNA content: DI= DNA IOD of the tested cell /DNA IOD average of normal cell [15]. If the measured cell was in the G0/G1 phase, its IOD was very close to the average IOD of normal cells, so the DI was 1 , that was 2C (1C was half of the DNA content of normal G0/G1 cells, so G0/G1 cells were $2 \mathrm{C}$ cells, namely diploid cells); When the cell was in G2/M phase, its IOD was about twice the IOD average of normal cells, so DI was 2, that was $4 \mathrm{C}$, and so on. Aneuploid cell peaks included: (1)single peak, which could appear in different positions, mostly between $2 \mathrm{C} \sim 4 \mathrm{C}$; (2) double peaks, which could appear in a variety of tumors, DI of the second peak was often twice that of the first peak; (3)multi-peaks, the histogram showed different heights like Manhattan houses, and the appearance of multiple peaks indicated that the chromosome structure of the tumor was very unstable [15].

After stained by Feulgen staining, all the nuclei on the slide were scanned on the automatic LD DNA-ICM. When the DI values of aneuploid cells formed a peak between 1.1 1.9; or there were more than 3 cells with DI larger than 2.5, namely larger than $5 \mathrm{C}$; or the number of cells with $\mathrm{DI}=2$ accounted for more than $10 \%$ of the total tested cells, these were used as positive indicators for DNA quantitative diagnosis of cancerous pleural / peritoneal effusion [15]. As shown in Figure 2, LD DNA-ICM could show the total number of epithelial cells, the number of cells greater than $5 \mathrm{C}$, the $C$ values of top 20 cells with the highest DNA content and aneuploid peaks in the report.

\section{Results}

3.1 In 591 patients analyzed, the median age was 66 years old, ranging from 28 to 93 years. 226 patients were older than 66 years old (38.2\%), and 365 patients were less than or equal to 66 years old $(61.8 \%)$. As for gender, $257(43.5 \%)$ were men and $334(56.5 \%)$ were women. 213 of the 591 patients $(36.0 \%)$ had smoking history and 378 (64.0\%) had not smoking history. All the patients were in advanced stage with pleural effusion and inoperable, so the histological specimens could not be obtained. Therefore, we could only diagnose lung adenocarcinoma by HE-staining cytological smear and immunocytochemistry, unable to further classify histopathological subtypes. All of them were stage IV according to the UICC/AJCC TNM staging system. We analyzed the relationship between EGFR mutations and clinicopathologic features, and found EGFR mutation status was correlated with gender $(\mathrm{p}=0.034)$ and smoking habits $(p=0.007)$, but not correlated with age $(p=0.483)$. The clinicopathological characteristics of those patients were summarized in Table 1.

3.2. All 591 patients were diagnosed with lung adenocarcinoma by HE staining and immunocytochemical staining, and EGFR gene detection and DNA quantitative analysis were successfully performed with their pleural effusions. As shown in Figure 3, EGFR mutations were found in 335 patients, including 9 with G719X mutation, 130 with 19DEL mutation, 4 with 20INS mutation, 155 with L858R mutation, 1 with L861Q mutation, 18 with combined mutations of 19DEL and T790M, 14 with combined mutations of L858R and T790M, 2 with combined mutations of 19DEL and L858R, 2 with combined mutations of G719X and S768I, and there were 256 patients without mutations.

3.3. Table 2 shows the comparison of DNA quantitative analysis between mutant group and non-mutant group. The maximum DI, the mean DI of the first 20 cells greater than $5 \mathrm{C}$, the percentage of cells greater than $5 \mathrm{C}$, and the number of cells greater than $9 \mathrm{C}$ of the first 20 cells in the mutant group were all higher than those in the non-mutant group, having statistical significance $(\mathrm{p}<0.001)$.

Table 3 shows the comparison of DNA aneuploid cell peaks between the mutant group and the non-mutant group. The peaks of aneuploid cells in the mutant group occurred more often than those in the non-mutant group, having statistical significance $(\mathrm{p}<0.001)$.

3.4. Table 4 shows the comparison of DNA quantitative analysis between 19DEL, L858R and non-mutant group. There were 150 cases in the 19DEL group (including 19DEL, 19DEL and T790M, 19DEL and L858R), 171 cases in the L858R group (including L858R, L858R and T790M, 19DEL and L858R), and 256 cases in non-mutant group. The maximum DI, the mean DI of the first 20 cells greater than $5 C$, the percentage of cells greater than $5 \mathrm{C}$ and the number of cells greater than $9 \mathrm{C}$ of the first 20 cells were compared in three groups, showing statistical significance: L858R > 19DEL > non-mutant group $(p<0.05)$; Table 5 shows the comparison of DNA 
aneuploid cell peaks among three groups: the aneuploid peaks showed a statistically significant difference in three groups $(p<0.001)$, but there was no
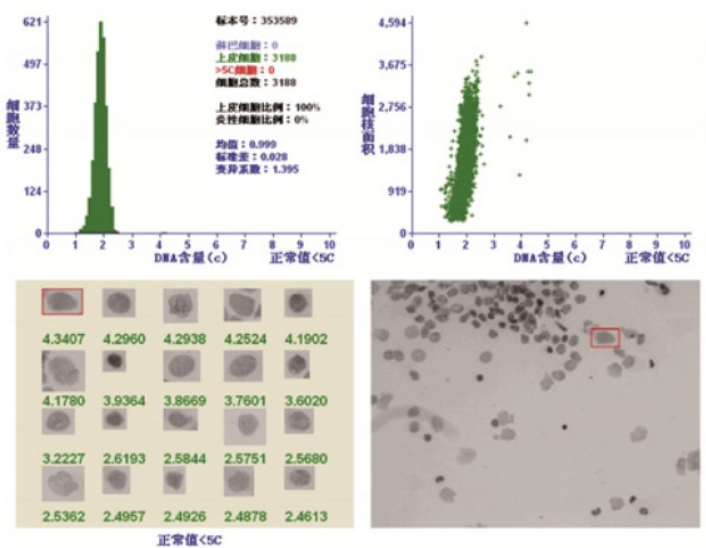

(A) No abnormal DNA ploid cells were observed.
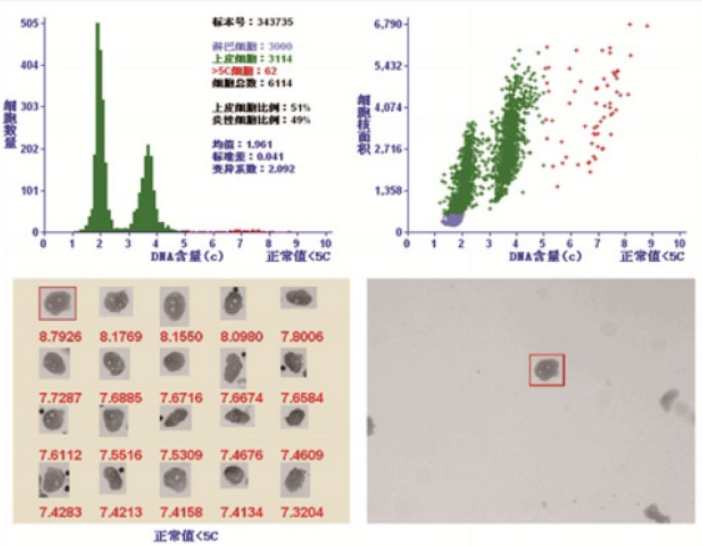

(C) Single peak of aneuploid cells was observed.
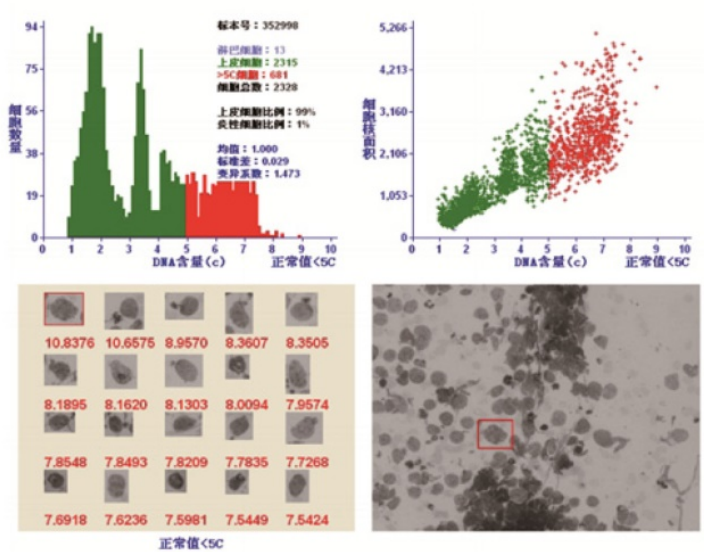

statistical difference between L858R group and 19DEL group when compared between two groups respectively.
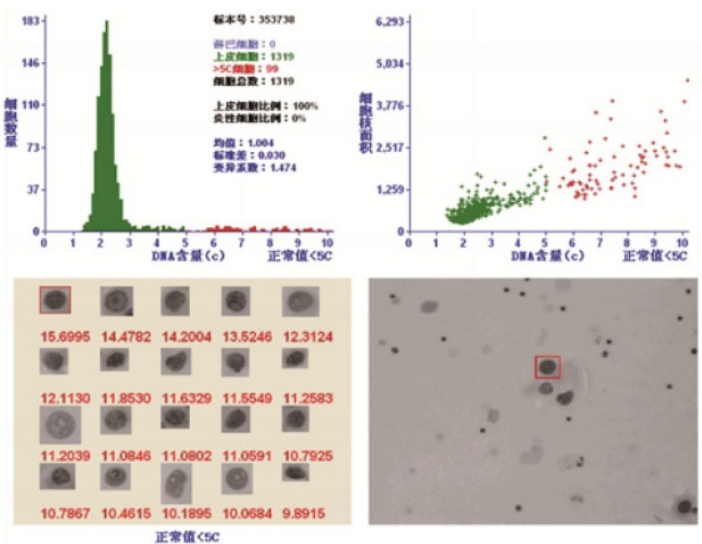

(B)Abnormal DNA ploid cells were observed, but no significant aneuploidy peak was observed.
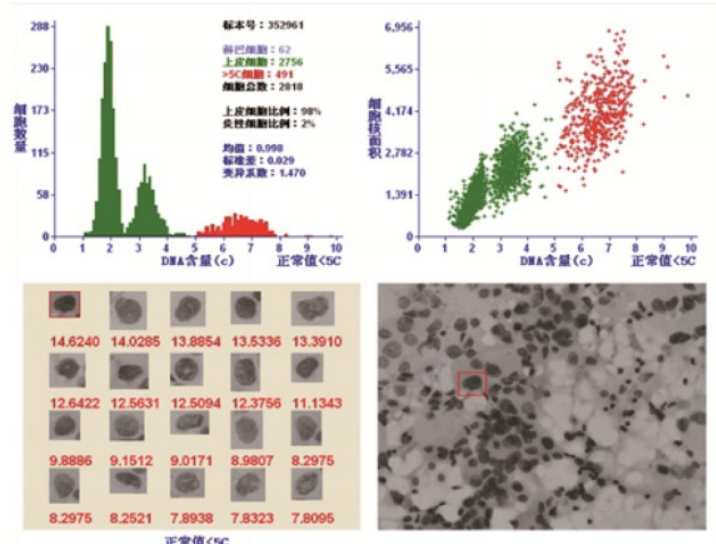

(D) Double peaks of aneuploid cells were observed.

(E) Multi-peaks of aneuploid cells were observed.

Figure 2. DNA quantitative analysis. 


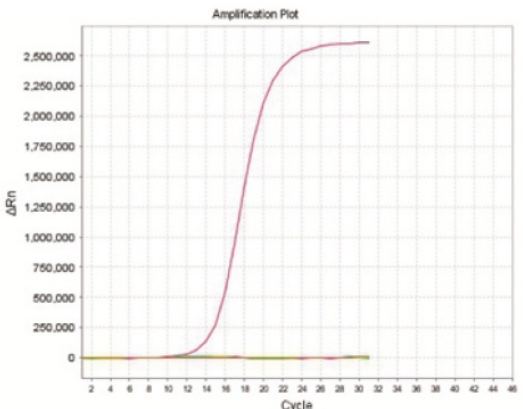

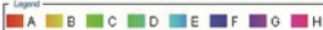

(A)EGFR gene detection: Negtive

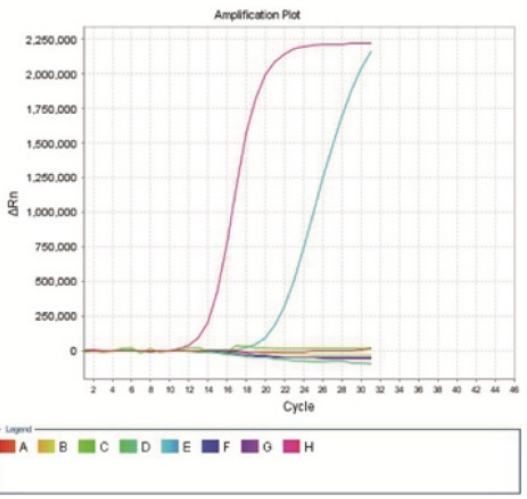

(D)EGFR 18(G719X) mutation

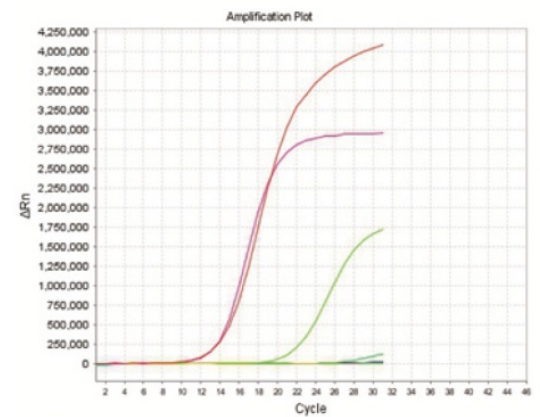

[A

(G) 19DEL and T790M mutations

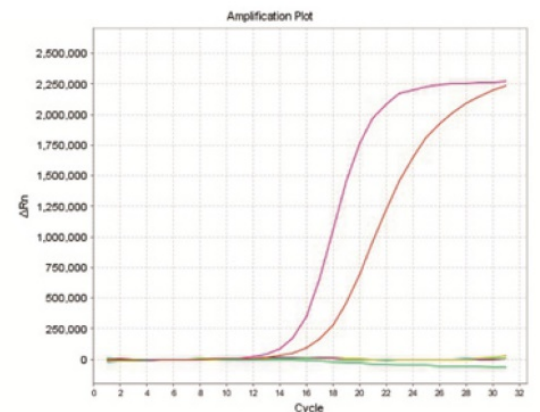

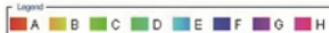

(B)EGFR 19DEL mutation

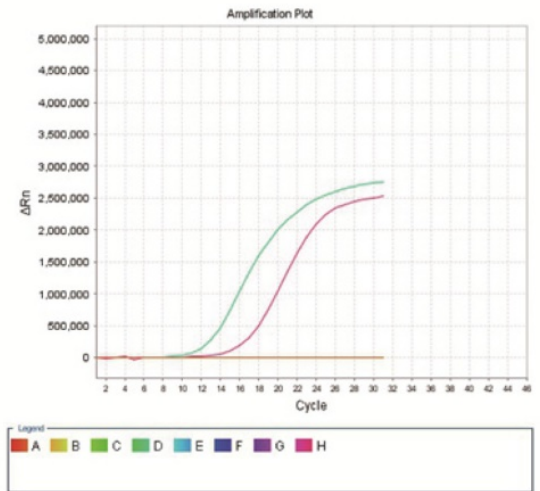

(E)EGFR 20 INS mutation

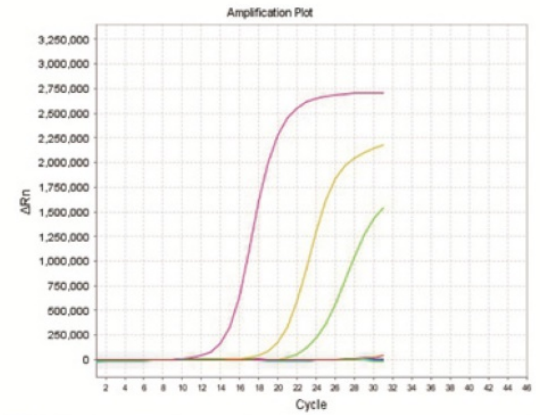

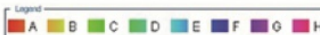

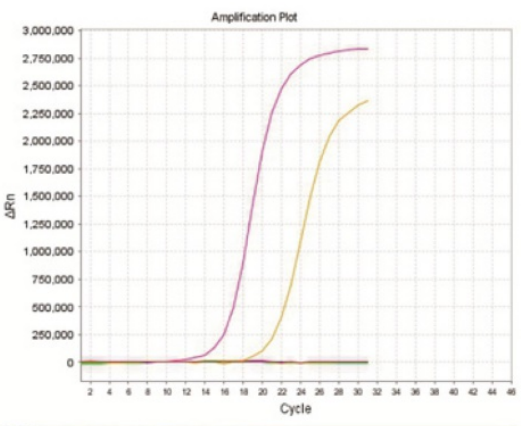

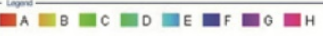

(C) EGFR 21(L858R) mutation

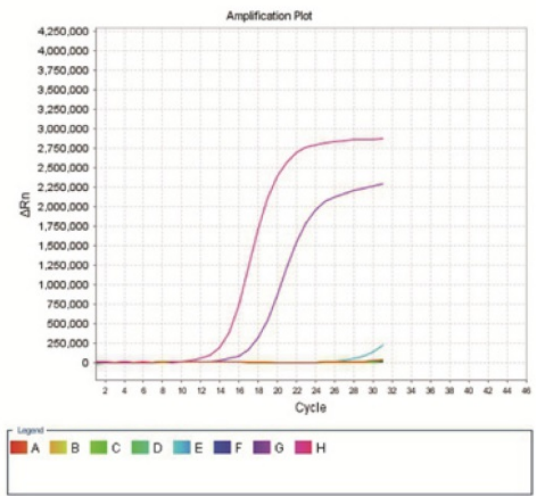

(F)EGFR 21(L861Q) mutation

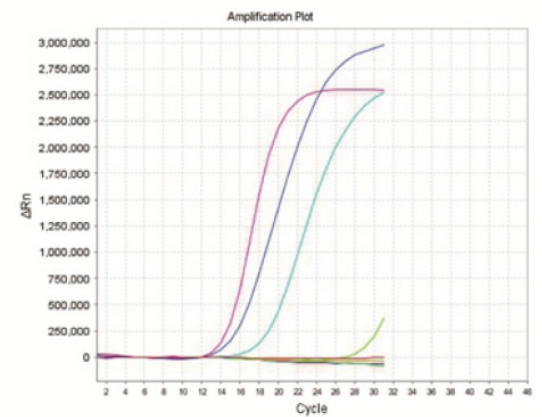

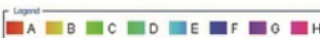

(I)G719X and S768I mutations

Figure 3. EGFR gene mutation results.

(H) L858R and T790M mutations

Table 1. Clinicopathological features of patients with lung adenocarcinoma.

\begin{tabular}{llllll}
\hline Group (EGFR) & WT number & MT number & Positive rate (\%) & $\chi^{2}$ & P value \\
\hline Age (yr) & & & & 0.492 & 0.483 \\
$\leq 66$ & 154 & 211 & $57.8 \%$ & & \\
$>66$ & 102 & 124 & $54.8 \%$ & & \\
Gender & & & & 4.506 & 0.034 \\
Male & 124 & 133 & $51.7 \%$ & & \\
Female & 132 & 202 & $60.4 \%$ & & \\
\hline
\end{tabular}

\begin{tabular}{|c|c|c|c|c|}
\hline Smoking & & & & $\begin{array}{ll}7.403 & 0.007\end{array}$ \\
\hline Smoker & 108 & 105 & $49.3 \%$ & \\
\hline Non-smoker & 148 & 230 & $60.8 \%$ & \\
\hline TNM Stage & & & & \\
\hline IV & 256 & 335 & $56.7 \%$ & \\
\hline $\begin{array}{l}\text { Cytopathology } \\
\text { adenocarcinoma }\end{array}$ & 256 & 335 & $56.7 \%$ & \\
\hline
\end{tabular}


Table 2. The comparison of DNA quantitative analysis between the mutant group and the non-mutant group

\begin{tabular}{|c|c|c|c|c|c|c|c|c|}
\hline \multirow[t]{2}{*}{$\begin{array}{l}\text { EGFR } \\
\text { result }\end{array}$} & \multicolumn{4}{|c|}{ The maximum DI } & \multicolumn{4}{|c|}{$\begin{array}{c}\text { The mean DI of the first } 20 \text { cells } \\
\text { greater than } 5 \mathrm{C}\end{array}$} \\
\hline & Median & $\begin{array}{c}\text { Mean } \\
\text { rank }\end{array}$ & $\mathrm{T}$ & p & Median & $\begin{array}{c}\text { Mean } \\
\text { rank }\end{array}$ & $\mathrm{T}$ & $\mathrm{p}$ \\
\hline $\begin{array}{l}\text { Mutant } \\
\text { group }\end{array}$ & 6.1224 & 317.37 & 35719.50 & $<0.001$ & 4.3987 & 323.35 & 33719.00 & $<0.001$ \\
\hline $\begin{array}{l}\text { Non-mutant } \\
\text { group }\end{array}$ & 5.5992 & 268.03 & & & 3.9988 & 260.21 & & \\
\hline \multirow[t]{2}{*}{$\begin{array}{l}\text { EGFR } \\
\text { result }\end{array}$} & \multicolumn{4}{|c|}{$\begin{array}{c}\text { The percentage of cells greater } \\
\text { than } 5 \mathrm{C}\end{array}$} & \multicolumn{4}{|c|}{$\begin{array}{c}\text { The number of cells greater } \\
\text { than } 9 \mathrm{C}\end{array}$} \\
\hline & Median & $\begin{array}{c}\text { Mean } \\
\text { rank }\end{array}$ & $\mathbf{T}$ & $\mathrm{p}$ & Median & $\begin{array}{c}\text { Mean } \\
\text { rank }\end{array}$ & $\mathbf{T}$ & $\mathrm{p}$ \\
\hline $\begin{array}{l}\text { Mutant } \\
\text { group }\end{array}$ & 3.7521 & 330.82 & 31214.50 & $<0.001$ & 7 & 320.83 & 34561.50 & $<0.001$ \\
\hline $\begin{array}{l}\text { Non-mutant } \\
\text { group }\end{array}$ & 1.7445 & 250.43 & & & 3 & 263.51 & & \\
\hline
\end{tabular}

Table 3. The comparison of DNA aneuploid cell peaks between the mutant group and the non-mutant group

\begin{tabular}{llllllll}
\hline & $\begin{array}{l}\text { Single } \\
\text { peak }\end{array}$ & $\begin{array}{l}\text { Double } \\
\text { peak }\end{array}$ & $\begin{array}{l}\text { Multi-peak None } \\
\text { peak }\end{array}$ & $\begin{array}{l}\text { Mean } \\
\text { rank }\end{array}$ & T & p \\
\hline $\begin{array}{l}\text { Mutant group } \\
124\end{array}$ & 38 & 47 & 126 & 320.14 & $34793.50<0.001$ \\
$\begin{array}{l}\text { Non-mutant } \\
\text { group }\end{array}$ & 59 & 15 & 33 & 149 & 264.41 & & \\
\hline
\end{tabular}

Table 4. The comparison of DNA quantitative analysis among the 19DEL group, L858R group and the non-mutant group

\begin{tabular}{|c|c|c|c|c|c|c|c|c|}
\hline \multirow[t]{2}{*}{ EGFR result } & \multicolumn{4}{|c|}{$\begin{array}{l}\text { The percentage of cells greater } \\
\text { than } 5 \mathrm{C}\end{array}$} & \multicolumn{4}{|c|}{$\begin{array}{c}\text { The number of cells greater } \\
\text { than } 9 \mathrm{C}\end{array}$} \\
\hline & Median & $\begin{array}{c}\text { Mean } \\
\text { rank }\end{array}$ & $\mathbf{H}$ & $\mathrm{p}$ & Median & $\begin{array}{l}\text { Mean } \\
\text { rank }\end{array}$ & $\mathbf{H}$ & $\mathrm{p}$ \\
\hline 19DEL & 2.9510 & 296.1 & 42.00 & $<0.001$ & 5 & 293.51 & 23.48 & $<0.001$ \\
\hline L858R & 5.9214 & 350.17 & & & 9 & 334.70 & & \\
\hline $\begin{array}{l}\text { Non-mutant } \\
\text { group }\end{array}$ & 1.7445 & 243.94 & & & 3 & 255.83 & & \\
\hline \multirow[t]{2}{*}{ EGFR result } & \multicolumn{4}{|c|}{ The maximum DI } & \multicolumn{4}{|c|}{$\begin{array}{c}\text { The mean DI of the first } 20 \\
\text { cells greater than } 5 \mathrm{C}\end{array}$} \\
\hline & Median & $\begin{array}{c}\text { Mean } \\
\text { rank }\end{array}$ & $\mathbf{H}$ & $\mathrm{p}$ & Median & $\begin{array}{l}\text { Mean } \\
\text { rank }\end{array}$ & $\mathbf{H}$ & $\mathrm{p}$ \\
\hline 19DEL & 6.1449 & 304.70 & 12.82 & 0.002 & 4.2845 & 291.46 & 27.86 & $<0.001$ \\
\hline L858R & 6.0887 & 316.26 & & & 4.5405 & 340.2 & & \\
\hline $\begin{array}{l}\text { Non-mutant } \\
\text { group }\end{array}$ & 5.5992 & 261.59 & & & 3.9988 & 253.36 & & \\
\hline
\end{tabular}

Table 5. The comparison of DNA aneuploid cell peaks among the 19DEL group, L858R group and the non-mutant group

\begin{tabular}{|c|c|c|c|c|c|c|c|}
\hline & $\begin{array}{l}\text { Single } \\
\text { peak }\end{array}$ & $\begin{array}{l}\text { Double } \\
\text { peak }\end{array}$ & Multi-peak & $\begin{array}{l}\text { None } \\
\text { peak }\end{array}$ & $\begin{array}{l}\text { Mean } \\
\text { rank }\end{array}$ & $\mathrm{H}$ & $\mathrm{p}$ \\
\hline 19DEL & 61 & 15 & 15 & 59 & 300.84 & 18.93 & $<0.001$ \\
\hline L858R & 58 & 22 & 29 & 62 & 323.52 & & \\
\hline $\begin{array}{l}\text { Non-mutant } \\
\text { group }\end{array}$ & 59 & 15 & 33 & 149 & 259.00 & & \\
\hline
\end{tabular}

\section{Discussion}

It is well known that lung adenocarcinomas with or without EGFR mutations have shown different drug effects against EGFR inhibitors. But EGFR is an oncogene; the abnormality of its related pathways is closely associated with tumor development, invasion, metastasis and drug resistance [1-4, 16-19]. Up till now it remains unclear and controversial whether there is a difference in malignant degree and prognosis between patients with EGFR mutations and those without mutations. Some studies have reported that patients with EGFR mutations were associated with a better prognosis compared with those without EGFR mutations, but most of them were based on the use of EGFR-TKI [20-23]. Two studies from Tetsuya Isaka et al [24] and Masaya Yotsukura et al [25] have reported patients with EGFR mutations in operable early-stage lung adenocarcinoma had a better RFS because of its higher incidence of lepidic growth pattern, adenocarcinoma in situ and minimally invasive adenocarcinoma, which rarely recur after resection of the lung when compared with those without EGFR mutations, but there was no significant difference in OS. However whether the histological subtype of lung adenocarcinoma is a prognostic factor remains controversial [26-28]. In contrast, some researchers [29, 30] have found that lung adenocarcinomas harboring some EGFR mutations exhibited increased cancer cell invasive ability and promoted malignant pleural effusion formation, and Zhu et al [31] have reported that Mt has a higher TP53 mutation rate and a higher Ki67 expression compared with $\mathrm{Wt}$, suggesting that $\mathrm{Mt}$ is more aggressive. So it is controversial and unclear if and how different EGFR mutation status affects the biological behavior of lung adenocarcinoma without using EGFR-TKI. We want to find an objective and molecular-based indicator to examine the effect of EGFR mutation status on the biological behavior of lung adenocarcinoma. Many studies [32-37] have demonstrated that DNA aneuploidy represents chromosomal instability and is the most common genetic abnormality in malignant cells related to the development of tumor. Njølstad et al [38] investigated DNA ploidy in curettage specimens of 785 endometrial carcinomas, and found non-diploid curettage is significantly associated with aggressive clinicopathological phenotype, lymph node metastasis, and poor survival in endometrial cancer. Maounis et al [39] reported that DNA ploidy, as determined by image analysis, provided an independent prognostic parameter for patients with NSCLC and thus, could be used to identify a subset of patients with more aggressive tumors. Other researches [40,41] have demonstrated high aneuploid DNA content was related to higher incidence of vessel invasion and lymph node metastasis. It has been identified by many studies that DNA content or DNA aneuploidy is an independent prognostic factor in many cancers [9-14, 42-49]. So we chose DNA as an objective genetic indicator to evaluate the biological behavior of lung adenocarcinoma in different EGFR mutation status. 
The results of this study have shown that the mutant group had higher DI values, more aneuploid cells and more frequent aneuploid peaks compared with the non-mutant group; L858R group had higher DNA content, more aneuploid cells and peaks, suggesting more genetic instability and malignancy when compared with 19Del group, consistent with previous studies $[29,50]$.

Based on the previous researches above mentioned, our study suggests that advanced lung adenocarcinomas with EGFR mutations are more aggressive than those without EGFR mutations.

Our study had several limitations. First, follow-up and survival analysis were not performed, so we are not sure if EGFR mutation status in advanced lung adenocarcinoma is an independent factor affecting prognosis. Second, It is not rigorous enough to evaluate the malignancy of tumor only by DNA content, although most reports have demonstrated that high DNA content, more aneuploid cells are closely related to tumor malignancy and poor prognosis, but a few studies have shown that the level of DNA content and the number of aneuploid cells are not independent factors affecting prognosis [51].

The effect of EGFR mutation status on tumor malignancy and prognosis is interfered by many factors, such as tumor stage and treatment method, etc. Our next study is to further investigate if EGFR mutation status and DNA aneuploidy are independent factors affecting the prognosis and survival of patients with lung adenocarcinomas by supplementing and refining follow-up data, and to design basic experiments to test whether different levels of DNA aneuploidy can change the proliferation, invasion and metastasis ability of lung adenocarcinoma cells.

\section{Conclusion}

This study has shown that there were significant differences in the value of DNA content, the number of aneuploid cells and the frequency of aneuploid peaks between EGFR mutant group and non-mutant group, the mutant group had higher DI values, more aneuploid cells and more frequent aneuploid peaks compared with the non-mutant group, suggesting that advanced lung adenocarcinomas with EGFR mutations were more aggressive than those without EGFR mutations.

\section{Competing Interests}

The authors have declared that no competing interest exists.

\section{References}

[1] Herbst RS. Review of epidermal growth factor receptor biology. Int J Radiat Oncol Biol Phys. 2004; 59(Suppl 2): 21-26.

[2] Han W, Lo HW. Landscape of EGFR signaling network in human cancers: biology and therapeutic response in relation to receptor subcellular locations. Cancer Lett. 2012;318(2):124-134.

[3] Tan X, Thapa N, Sun Y, et al. A kinase-independent role for EGF receptor in autophagy initiation. Cell. 2015;160(1-2):145-160.

[4] Fitzgerald TL, Lertpiriyapong K, Cocco L, et al. Roles of EGFR and KRAS and their downstream signaling pathways in pancreatic cancer and pancreatic cancer stem cells. Adv Biol Regul. 2015;59:65-81.

[5] Gómez XE. Soto A. Gómez MA Survival and prognostic factors in non-small cell lung cancer patients with mutation of the EGFR gene treated with tyrosine kinase inhibitors in a Peruvian hospital. Am J Cancer Res. 2019;9(5):1009-1016.

[6] Mok TS, Wu YL, Thongprasert S, et al. Gefitinib or carboplatin-paclitaxel in pulmonary adenocarcinoma. The New England journal of medicine. 2009;361(10):947-957

[7] Mitsudomi T, Morita S, Yatabe Y, et al. Gefitinib versus cisplatin plus docetaxel in patients with non-small-cell lung cancer harbouring mutations of the epidermal growth factor receptor (WJTOG3405): an open label, randomised phase 3 trial. Lancet Oncol. 2010;11(2):121-128.

[8] Rosell R, Carcereny E, Gervais $R$, et al. Erlotinib versus standard chemotherapy as first-line treatment for European patients with advanced EGFR mutation-positive non-small-cell lung cancer (EURTAC): a multicentre, open-label, randomised phase 3 trial. Lancet Oncol. 2012;13(3):239-246.

[9] Zaino RJ, Davis AT, Ohlsson-Wilhelm BM, et al. DNA content is an independent prognostic indicator in endometrial adenocarcinoma. A Gynecologic Oncology Group study. Int J Gynecol Pathol. 1998;17(4):312-319.

[10] Mangili G, De Marzi P, Viganò R, et al. Identification of high risk patients with endometrial carcinoma. Prognostic assessment of endometrial cancer. Eur J Gynaecol Oncol. 2002;23(3):216-220.

[11] Pradhan M, Abeler VM, Danielsen HE, et al. Image cytometry DNA ploidy correlates with histological subtypes in endometrial carcinomas. Mod Pathol. 2006;19(9):1227-1235

[12] Maounis NF, Chorti M, Apostolakis E, et al. Prognostic impact of Deoxyribonucleic acid (DNA) image analysis cytometry and immunohistochemical expression of Ki67 in surgically resected non-small cell lung cancers. Cancer Detect Prev. 2006;30(6):507-514.

[13] Yildirim-Assaf $S$, Coumbos A, Hopfenmüller $W$, et al. The prognostic significance of determining DNA content in breast cancer by DNA image cytometry: the role of high grade aneuploidy in node negative breast cancer. J Clin Pathol. 2007;60(6):649-655.

[14] Janisson-Dargaud D, Durlach A, Lorenzato M, et al. Aneuploidy, but not Ki-67 or EGFR expression, is associated with recurrences in basal cell carcinoma. J Cutan Pathol. 2008;35(10):916-921.

[15] Sun XR, Wang J. DNA quantitative cytology. Hubei, China: Hubei science and technology press; 2018

[16] Mitsudomi T, Kosaka T, Yatabe Y. Biological and clinical implications of EGFR mutations in lung cancer. Int J Clin Oncol. 2006;11(3):190-198.

[17] Kosaka T, Yatabe Y, Endoh $\mathrm{H}$, et al. Mutations of the epidermal growth factor receptor gene in lung cancer: biological and clinical implications. Cancer Res. 2004;64(24):8919-8923.

[18] Nguyen ON, Vuong LD, Truong VL, et al. Genetic and epigenetic alterations of the EGFR and mutually independent association with BRCA1, MGMT, and RASSF1A methylations in Vietnamese lung adenocarcinomas. Pathol Res Pract. 2019;215(5):885-892.

[19] Nakano T, Yamamoto H, Hashimoto K, et al. HER2 and EGFR gene copy number alterations are predominant in high-grade salivary mucoepidermoid carcinoma irrespective of MAML2 fusion status. Histopathology. 2013;63(3):378-392.

[20] Kwon BS, Park JH, Kim S, et al. Survival benefit of first-generation epidermal growth factor receptor-tyrosine kinase inhibitors in female with advanced lung cancer. Tumori. 2019;105(3):216-224.

[21] Mitsudomi T, Morita S, Yatabe Y, et al. Gefitinib versus cisplatin plus docetaxel in patients with non-small-cell lung cancer harbouring mutations of the epidermal growth factor receptor (WJTOG3405): an open label, randomised phase 3 trial. Lancet Oncol. 2010;11(2):121-128.

[22] Inoue A, Kobayashi K, Maemondo M, et al. Updated overall survival results from a randomized phase III trial comparing gefitinib with carboplatin-paclitaxel for chemo-naive non-small cell lung cancer with sensitive EGFR gene mutations (NEJ002). Ann Oncol. 2013;24(1):54-59.

[23] Yang JC, Wu YL, Schuler $M$, et al. Afatinib versus cisplatin-based chemotherapy for EGFR mutation-positive lung adenocarcinoma (LUX-Lung 3 and LUX-Lung 6): analysis of overall survival data from two randomised, phase 3 trials. Lancet Oncol. 2015;16(2):141-151.

[24] Isaka $\mathrm{T}$, Nakayama $\mathrm{H}$, Ito $\mathrm{H}$, et al. Impact of the epidermal growth factor receptor mutation status on the prognosis of recurrent adenocarcinoma of the lung after curative surgery. BMC Cancer. 2018;18(1):959.

[25] Yotsukura M, Yasuda H, Shigenobu T, et al. Clinical and pathological characteristics of EGFR mutation in operable early-stage lung adenocarcinoma. Lung Cancer. 2017;109:45-51.

[26] Oskarsdottir GN, Bjornsson J, Jonsson S, et al. Primary adenocarcinoma of the lung--histological subtypes and outcome after surgery, using the 
IASLC/ATS/ERS classification of lung adenocarcinoma APMIS. 2016;124(5):384-392.

[27] Zhao X, Zhang Y, Qian K, et al. Prognostic significance of the International Association for the Study of Lung Cancer/American Thoracic Society/European Respiratory Society classification of stage I lung adenocarcinoma: A retrospective study based on analysis of 110 Chinese patients. Thorac Cancer. 2017:8(6):565-571.

[28] Russell PA, Wainer Z, Wright GM, et al. Does lung adenocarcinoma subtype predict patient survival?: A clinicopathologic study based on the new International Association for the Study of Lung Cancer/American Thoracic Society/European Respiratory Society international multidisciplinary lung adenocarcinoma classification. J Thorac Oncol. 2011;6(9):1496-1504.

[29] Tsai MF, Chang TH, Wu SG, et al. EGFR-L858R mutant enhances lung adenocarcinoma cell invasive ability and promotes malignant pleural effusion formation through activation of the CXCL12-CXCR4 pathway. Sci Rep. 2015;5:13574.

[30] Nie Y, Gao W, Li N, et al. Relationship between EGFR gene mutation and local metastasis of resectable lung adenocarcinoma. World J Surg Oncol. 2017;15(1):55.

[31] Zhu WY, Hu XF, Fang KX, et al. Prognostic value of mutant p53, Ki-67, and TTF-1 and their correlation with EGFR mutation in patients with non-small cell lung cancer. Histol Histopathol. 2019; 34(11):1269-1278.

[32] Ghizoni JS, Sperandio M, Lock C, et al. Image cytometry DNA ploidy analysis: correlation between two semi-automated Methods. Oral Dis. 2018; 24(7):1204-1208

[33] Bondi J, Pretorius M, Bukholm I, et al. Large-scale genomic instability in colon adenocarcinomas and correlation with patient outcome. APMIS. 2009; 117(10):730-736 .

[34] Kinzler KW, Vogelstein B. Cancer-susceptibility genes. Gatekeepers and caretakers. Nature. 1997;386(6627):761-763.

[35] Holland AJ, Cleveland DW. Boveri revisited: chromosomal instability, aneuploidy and tumorigenesis. Nat Rev Mol Cell Biol.2009;10(7): 478-487.

[36] Kunkel TA, Resnick MA, Gordenin DA. Mutator specificity and disease: looking over the FENce. Cell. 1997;88(2):155-158

[37] Terada K. DNA ploidy in endometrial cancer: unfinished business? Ann. Oncol. 2012;23(5):1083-1084.

[38] Niølstad TS, Trovik J, Hveem TS, et al. DNA ploidy in curettage specimens identifies high-risk patients and lymph node metastasis in endometrial cancer. Br J Cancer. 2015;112(10):1656-1664.

[39] Maounis NF, Chorti M, Apostolakis E, et al. Prognostic impact of Deoxyribonucleic acid (DNA) image analysis cytometry and immunohistochemical expression of Ki67 in surgically resected non-small cell lung cancers. Cancer Detect Prev. 2006;30(6):507-514.

[40] Baba H, Korenaga D, Okamura T, et al. Prognostic Significance of DNA Content With Special Reference to Age in Gastric Cancer. Cancer.1989;63(9):1768-1772.

[41] Song T, Lee JW, Choi CH, et al. Ploidy and S-phase fraction are correlated with lymphovascular space invasion that is predictive of outcomes in endometrial cancer. Int J Clin Oncol. 2012;17(6) :590-597.

[42] Proctor L, Pradhan M, Leung S, et al. Assessment of DNA Ploidy in the ProMisE molecular subgroups of endometrial cancer. Gynecol Oncol. 2017;146(3):596-602

[43] Kamphues C, Al-Abadi N, Bova R, et al. The DNA index as a prognostic tool in hilar cholangiocarcinoma. J Surg Oncol. 2015;112(2) :214-218.

[44] Kamphues C, Al-Abadi H, Dürr A, et al. DNA index as a strong prognostic factor in patients with adenocarcinoma of the pancreatic head: results of a 5-year prospective study. Pancreas. 2013;42(5):807-812.

[45] Hellman K, Johansson H, Andersson S, et al. Prognostic significance of cell cycle- and invasion-related molecular markers and genomic instability in primary carcinoma of the vagina. Int J Gynecol Cancer. 2013;23(1):41-51.

[46] Habermann J, Lenander C, Roblick UJ, et al. Ulcerative colitis and colorectal carcinoma: DNA-profile, laminin-5 gamma2 chain and cyclin A expression as early markers for risk assessment. Scand J Gastroenterol. 2001;36(7):751-758.

[47] Lundgren C, Frankendal B, Silfversward C, et al. Laminin-5 gamma2-chain expression and DNA ploidy as predictors of prognosis in endometrial carcinoma. Med Oncol. 2003;20(2):147-156.

[48] Auer GU, Heselmeyer KM, Steinbeck RG, et al. The relationship between aneuploidy and p53 overexpression during genesis of colorectal adenocarcinoma. Virchows Arch.1994;424(4):343-347.

[49] Forsslund G, Esposti PL, Nilsson B, et al. The prognostic significance of nuclear DNA content in prostatic carcinoma. Cancer. 1992;69(6):1432-1439.

[50] Li R, Li Q, Lin S, et al. Prognostic implication of EGFR mutation status and subtype in resected lung adenocarcinoma patients irrespective of therapy. Clin Transl Oncol. 2019;21(3):298-303.

[51] Zargoun IM, Bingle L, Speight PM. DNA ploidy and cell cycle protein expression in oral squamous cell carcinomas with and without lymph node metastases. J Oral Pathol Med. 2017;46(9):738-743.

\section{Author Biography}

Dr Yun Du is a professor of Hebei Medical University and director of Cytology Department in the Fouth Hospital of Hebei Medical University. After graduating from Hebei Medical University in 1991, Dr.Yun Du was engaged in clinical work in the Fouth Hospital of Hebei Medical University for 7 years from 1991 to 1998. She has been working as a pathologist and cytologist in pathology and cytology department since 1999. From 2002 to 2005, she studied for a doctor's degree in pathology and pathophysiology at Hebei Medical University. Her research interests are tumor pathology and molecular pathology. She has published 2 SCI articles related to tumor develpment. 